\title{
Mobile Application Design with IoT for Environmental Pollution Awareness
}

\author{
Anthony Ramos-Romero ${ }^{1}$, Brighitt Garcia-Yataco ${ }^{2}$, Laberiano Andrade-Arenas ${ }^{3}$ \\ Facultad de Ciencias e Ingeniería \\ Universidad de Ciencias y Humanidades
}

\begin{abstract}
In the present study, we have seen that many people are affected by environmental pollution, so we proposed a mobile application prototype to facilitate awareness of this environmental problem. The methodology that will help us make this application will be the Scrum methodology, since it is adaptable to the constant changes in the mobile application development process. We will also use an Internet of Things and Fire based technology to collect data from the various air pollution sensors. Since users require a visualization of the contamination in real time. The mobile application to which users will automatically register will have easy access for use in monitoring and controlling atmospheric pollution, whose reception data will be through sensors. The result that has been obtained is that it was achieved with the implementation of the application that people are aware of the damage that these pollutants cause to the environment.
\end{abstract}

Keywords-Environmental pollution; internet of things; scrum; mobile app

\section{INTRODUCTION}

We are currently in a world immersed in environmental pollution and the negative effect it causes is evident, this is the cause of the continuous pollution that each of the people who live on planet earth do, throwing garbage, polluting rivers, seas without knowing the consequences that such actions can cause, which is why many developed and developing countries have a large number of people who get sick in a certain place and period of time. This makes environmental pollution one of the most relevant problems in the world, pollution levels grow causing serious consequences for health and the environment, air quality is getting worse, this causes major health problems. Being a great problem for the inhabitants of the planet, some countries use the IoT (internet of things) as a way of measuring the level of contamination of the environment but it is very limited since it is not very accessible for the inhabitants of the same [1].

According to the World Health Organization, air pollution around the world kills approximately 7 million people a year, either from vascular strokes, heart disease, lung cancer, as well as acute and chronic respiratory diseases [2].

In developed countries such as Russia, Turkey, South Korea, Japan and the United States, they have agricultural emissions that contain ammonia, which is one of the main sources of environmental pollution [3].

In China, it has reached such a degree that the fine PM (Particulate Material) in its air is PM 2.5, which means that there is a lot of pollution, therefore its inhabitants wear masks to prevent diseases that can cause such pollution [4].
In addition, its annual average concentrations of fine particles in the world vary between 8000 and 19,500 PM 2.5 particles, they are penetrated and can lodge deep in the lung tissue [5].

Likewise, in Latin America there are many countries with poor air quality, among them are Peru, Chile, Mexico, Brazil and Colombia as the main polluting countries because they are the countries with the highest oil production, also due to the number of vehicles that circulate. . emitting various polluting gases such as: carbon monoxide, carbon dioxide and methane [6].

From a closer point of view in Peru; Lima is the department with the highest rate of environmental pollution, due to the large number of vehicles that release carbon monoxide and PM 2.5 hydrocarbons and also due to the excess of waste dumped on the streets [6].

Currently some of the awareness solutions are based on processing data and converting it into information through stations at fixed points, capturing different types of gases in the environment, but only in established areas and many of these results are not available to all people. so they are not responsible for the great damage we are causing to the environment [7].

The IoT is a technology that consists of obtaining data from our environment through the use of electronic components, having various applications that can provide great benefit. One of these applications is the collection of data on the quality of the environment using sensors that have the ability to collect data on the levels of certain gases around us. These data, being interpreted in a correct way, will become a reliable source of information that can be displayed through a mobile application or web interfaces in real time to be seen by the general public, having a great impact on people's mentality, raising awareness about the quality of the environment that surrounds us, the same ones that being committed to their environment will pollute less, use less chemical products, this will result in a decrease in pollution rates [8].

Therefore, the objective of this research work is to carry out a mobile application with integration of the IoT that aims to make people aware of the damage they currently cause to the environment, demonstrating the level of air quality and gases that may be present, to Based on the data grouping analysis of the different electronic components that will be presented through a mobile application, the SCRUM methodology is proposed in turn with the implementation of emerging technologies such as IoT, Cloud Computing (Fire Base), Fog Computng ( Mobile Devices) and reactive programming. 
The present work is structured as follows, in Section II the methodology used with respect to development will be described. In Section III the technologies to be used as well as the IoT, Cloud Computing, the mobile application, among others, will be detailed. In Section IV the case study will be evidenced, forming friendly prototypes for better understanding, finally, in Section $\mathrm{V}$ the results will be discussed and finally in Section VI the conclusions.

\section{Methodology}

This section will detail the steps that will be followed for the development of the mobile application and IoT, using the Scrum Methodology, since the work rules it has are perfectly suitable for software development projects, in addition to being an organized process it consists in good practices, allowing teamwork and is open to change, giving this added value since emerging technologies are constantly changing (IoT) [9].

\section{A. Analysis}

Scrum is defined in three main roles which are the Scrum Master, the Product Owner and the development team.

The role of the scrum master is to ensure that the team is adopting the methodology, its practices, values and norms. $\mathrm{He}$ is the team leader, but he does not manage development. The Product Owner is a single person and represents the stakeholders, is responsible for maximizing the value of the product and the work of the development team; Its functions include managing the list of required functionalities or Product Backlog.

For its part, the development team is responsible for converting what the client wants, the Product Backlog, into functional iterations of the product; the development team does not have hierarchies, all its members have the same level and position: developer. The optimal team size is between three and nine people [10].

This process flow of the Scrum methodology consists in that users identify the system requirements (needs to have information about the environment in a mobile application) that are the user stories, then the development team orders and prioritizes these user stories for your prompt development [11].

In Fig. 1, we can see the steps that must be carried out to make an adequate use of the Scrum methodology.

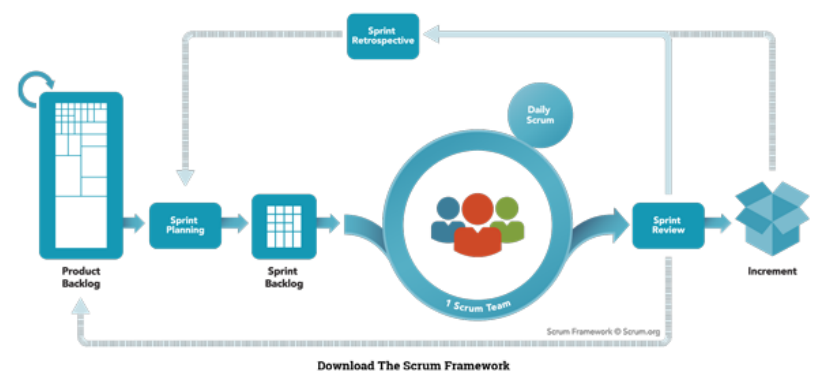

Fig. 1. Scrum.

To better understand the methodology, we find the main Scrum stages in which they are based on sprints, which the team proposes to generate a deliverable product. In each of them, mini projects are developed that serve to improve the effectiveness of the project, this being of great impact for software development projects and IoT [10].

These are the main stages of the scrum:

1) Sprint planning: This stage takes place in the Sprint Planning meeting where your work plan is defined: what will be delivered and how it will be accomplished. That is, the design of the system and the estimate of the amount of work. This activity lasts eight hours for a one-month Sprint. If the Sprint has a shorter duration, the time is allocated proportionally [12].

2) Development stage: At this stage, sprint managers must ensure that last minute changes are not generated that affect the objectives. In addition, they must ensure that they meet the established deadlines [13].

3) Sprint Review: The Sprint Review occurs at the end of the Sprint and lasts for four hours for a one-month project (or a proportion of that time if the duration is shorter). At this stage: the project owner reviews what was done, identifies what was not done, and analyzes the Product Backlog; the development team tells what problems they found and how they were solved, and shows the product and how it works [12].

Fig. 2 provides an overview of the development flow of a Sprint.

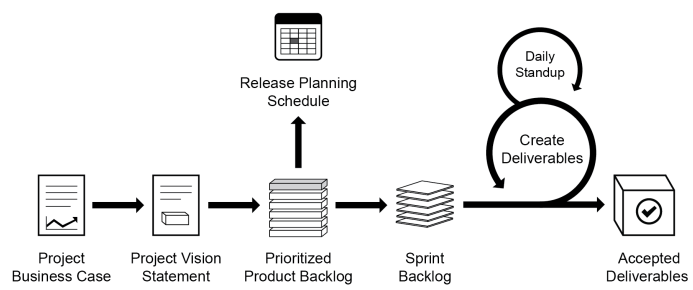

Fig. 2. Scrum Flow for a Sprint.

For the implementation the following steps will be carried out:

I. Product Backlog: It consists of identifying the user stories that become the user requirements and giving them a priority level, the backlog comes from a hundred of the list of user stories ordered and prioritized [14].

II. Sprint portfolio: It is a segmentation of the prioritized and ordered user stories, where the development team determines the increments that will be developed throughout the project[15].

III. Sprint planning meeting: It is the Sprint planning meeting based on the Product Backlog and they participate: Product Owner (responsible for the subject) who prioritizes the tasks to be included in the Sprint Backlog, the Scrum Master and the Development Team [15]. 


\section{TECHNOLOGY}

\section{A. Internet of Things}

The internet of things is changing the world and this because it helps us obtain data from nature or even from electronic devices that have electronic components capable of capturing data and converting it into information. In this present investigation we will make use of it, we will use IoT technology to capture the data of gases or substances that may exist in the air, we will proceed to analyze them and convert them into information to be able to visualize them [16].

1) Architecture: In Fig. 3, we can visualize an architecture that consists of a section where the IoT devices are located that connect to the cloud computing through a gateway to the internet, said cloud computing has multiple services that are used to process the data obtained from the sensors, turning them into information that can be viewed from a web portal and even a mobile application.

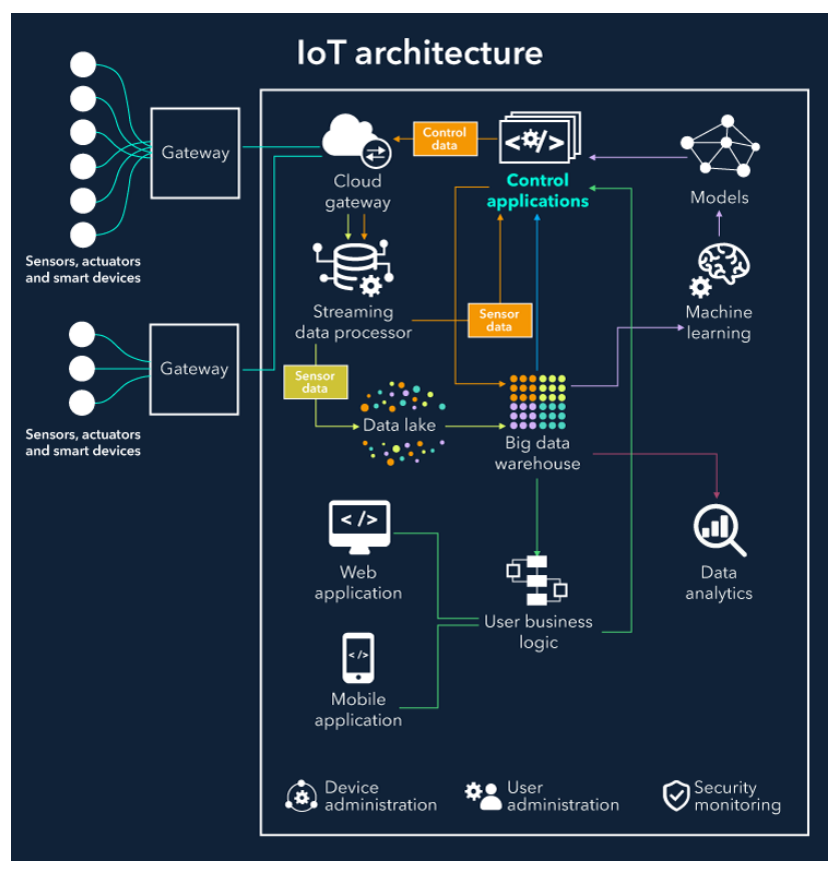

Fig. 3. Architecture IoT.

Next, the following layers belonging to the architecture of IoT technology will be described.

- Perception Cloak: This layer is responsible for collecting all kinds of information through sensors that capture and represent the information [16].

- Network layer: This layer is responsible for the transmission of information through various basic networks, which are the internet, mobile communication network, wireless network, satellite networks, network infrastructure and communication protocols [16].

- Physical layer: This layer is in charge of intelligent computing in which it is organized through the network and the cloud [16].

- Application layer: This layer ensures that users can access the Internet of Things through the use of a cell phone or computer. [16].

The sensors in charge of obtaining data from the environment cannot manipulate or treat them, so we will use Arduino. The communication of the Arduino and the mobile device will be via Bluetooth. There is a module for Arduino that meets this objective [17]. Likewise, the mobile application will be in charge of communicating with the cloud services by sending the data obtained by the sensors. The development will be carried out on the official development platform for projects made with Arduino [18].

Sensors capable of capturing and emitting data on the different polluting gases that exist in the air, as shown in Table I where we list the electronic components that meet the established requirements.

TABLE I. SENSORS

\begin{tabular}{|l|l|}
\hline \multicolumn{2}{|c|}{ Electronic components } \\
\hline 1. MQ-7 & Carbon monoxide \\
\hline 2. MQ-2 & Methane, Butane, Smoke \\
\hline 3. MQ-6 & Butane \\
\hline 4. MQ-8 & Hydrogen \\
\hline 5. MQ-131 & Ozone \\
\hline
\end{tabular}

These sensors are electrochemical and vary their resistance when exposed to certain gases, internally it has a heater in charge of increasing the internal temperature and with this the sensor can react with the gases causing a change in the resistance value [19].

- MQ-7: Its function is to detect carbon monoxide in the air, since it has a high sensitivity.

- MQ-2: Its function is to detect LPG, propane, methane, alcohol, hydrogen and smoke.

- MQ-6: Its function is to detect LPG, butane, propane and methane.

- MQ-8: Its function is to detect hydrogen concentrations in the air.

- MQ-131: Its function is to detect ozone gas concentrations in the air.

\section{B. Mobile App}

Currently most people have a mobile device, so for the research topic we will develop a mobile application that will be in charge of displaying the information processed by the FireBase services, information such as the level of pollutants found in the air anywhere in the world.

The interaction between the Arduino and the mobile application will be making use of consumption by the Arduino and exposure of Rest services (API) by the mobile application, all of this using reactive programming. The development will be carried out with the Kotlin programming language, using FireBase services among other technologies [20]. 


\section{FireBase}

It is a platform for the development of mobile applications that offers us a wide variety of services as well as hosting, Real-time database, authentication, among others. The application will use some of the services offered by FireBase such as a real-time database, hosting, among others [21].

\section{Prototype}

For the realization of the prototypes, the moqups tool will be used, which provides us with a great variety of modern components that can be used for their realization [22].

\section{CASE STUdy}

In this section we will see the construction of an air quality control and administration system through IoT and the planning of the sprint of each of the prototypes with the estimates of the times in which it is being carried out in the mobile development.

Fig. 4 represents the operation of the IoT architecture in the hands of the mobile application integrated in air quality through sensors.

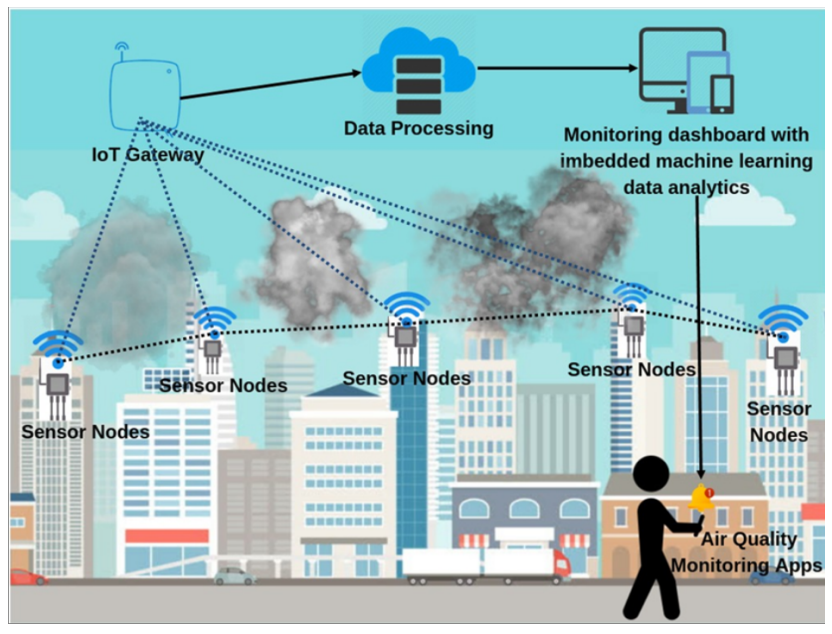

Fig. 4. IoT-based Air Monitoring System.

\section{A. Sprint Planning}

- As a user, I need to be able to create a user account to enter the application.

- As a user, I would like to be able to link my mobile device with the sensors via Bluetooth to establish a data collection point in my house to also be able to configure the data reading time and if the information travels to the server.

- As a citizen, I would like to know the gases that surround me to become aware of my actions against the environment.

- As a citizen, I would like to visualize the areas of my city with their respective pollution rates.

\section{B. Development Stage}

1) Time estimate: In this phase we will see the duration of each of the sprints as shown in Table II.

TABLE II. DURATION OF SPRINTS

\begin{tabular}{||l|l|l||}
\hline Name & Duration & Sprint \\
\hline Mobile app & \multicolumn{2}{|c||}{4 Month } \\
\hline Login screen & 2 weeks & 1 \\
\hline Sensor Integration with Arduino & 2 weeks & 1 \\
\hline Navigation menu & 2 weeks & 1 \\
\hline Registration Screen & 2 weeks & 1 \\
\hline Configuration screen & 2 weeks & 2 \\
\hline Arduino integration with Mobile device & 2 weeks & 2 \\
\hline Gas Dashboard screen & 2 weeks & 2 \\
\hline Location Dashboard screen & 2 weeks & 3 \\
\hline
\end{tabular}

2) Product scope: It is the estimate of the time it takes for the team to have the points of the user stories, for which the estimates of the team's scope will be detailed in the following graph.

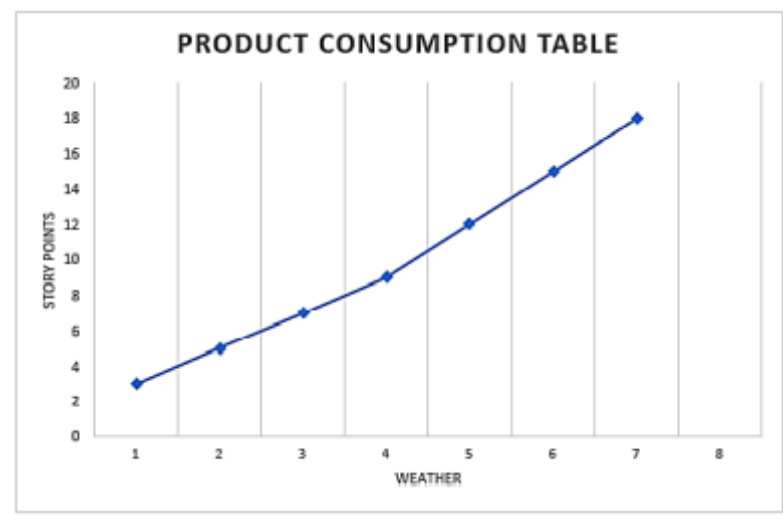

Fig. 5. Product Definition

3) Mobile app prototypes: In this stage we will see the creation of the design of the mobile application that we will carry out and we will detail the functions that each of the modules will have as we see Fig. 6, Fig. 7, Fig. 8, Fig. 9, Fig. 10 and Fig. 11.

\section{4) Mobile app prototype increases:}

- Increment 1 - Login, Register and Menu.

As shown in Fig. 3 to 5, this section is used to enter and register to the system by email or a social network, in turn we show the navigation screen, which has a user-friendly aspect.

- Increment 2 - Configuration and Monitor of gases in the air

The increment consists of two screens (Fig. 6 and 7), one of them is used to configure both the Bluetooth, the time interval to read the data from the sensors and send them to the server and the dashboard screen that is completely informative, we will show the different types of gases that we have around us, the user will be able to view graphs with percentages by type of gas and in turn a list of sensor reading data records. 


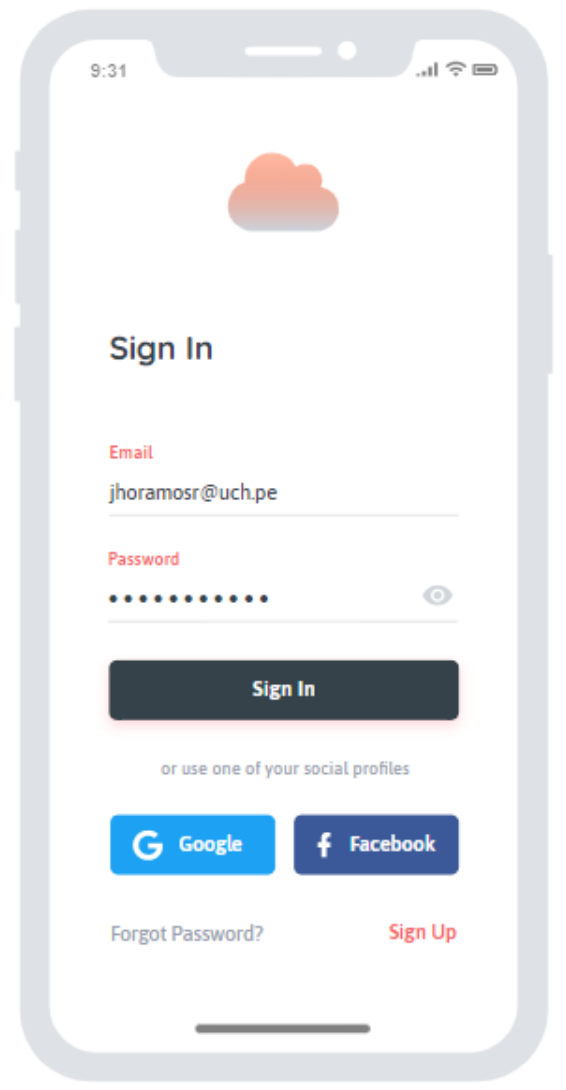

Fig. 6. Login Screen.

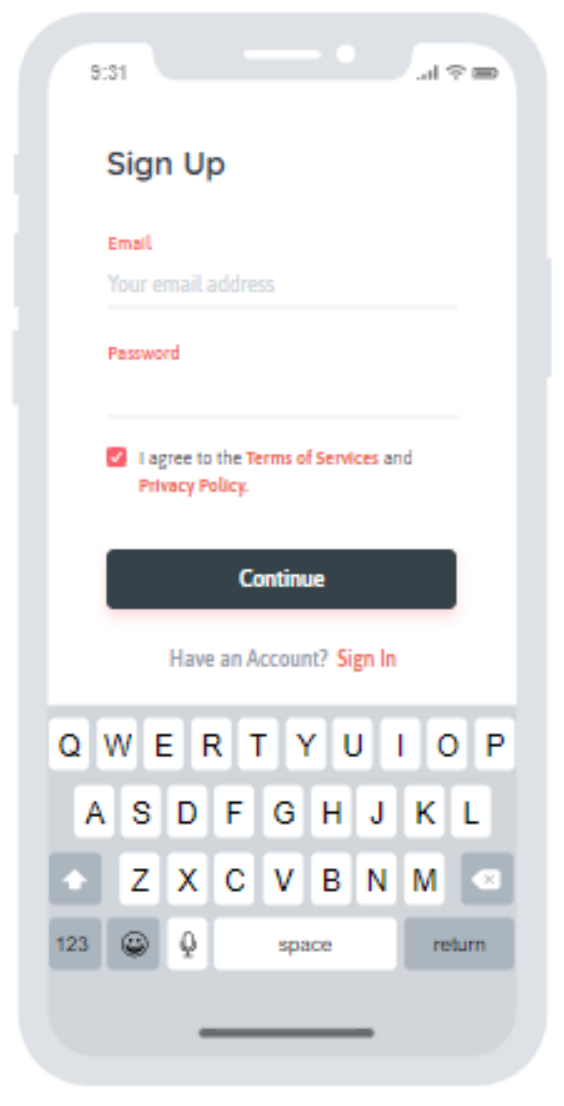

Fig. 7. Registration Screen.

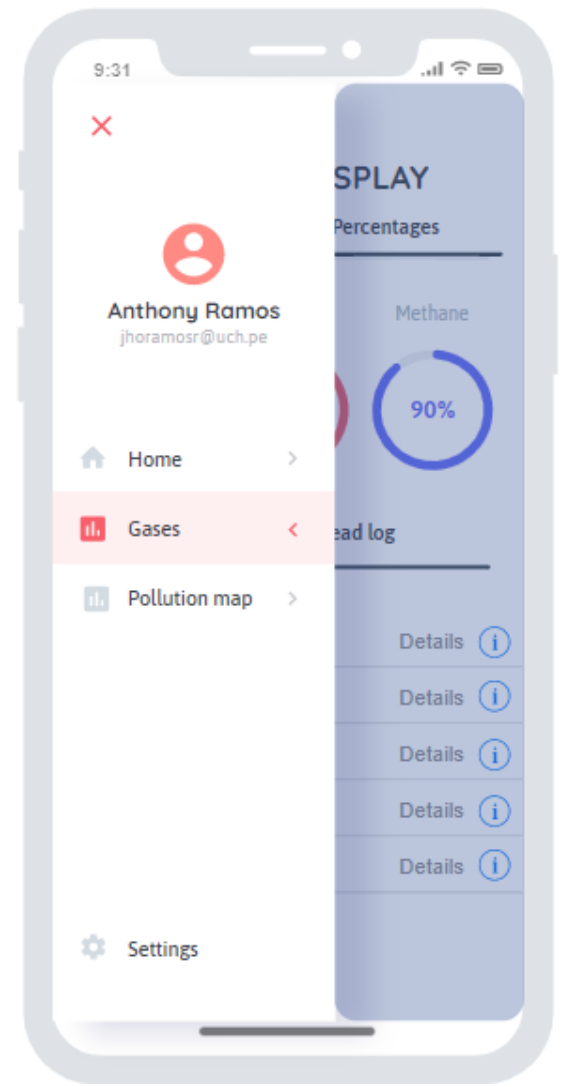

Fig. 8. Navigation Menu.

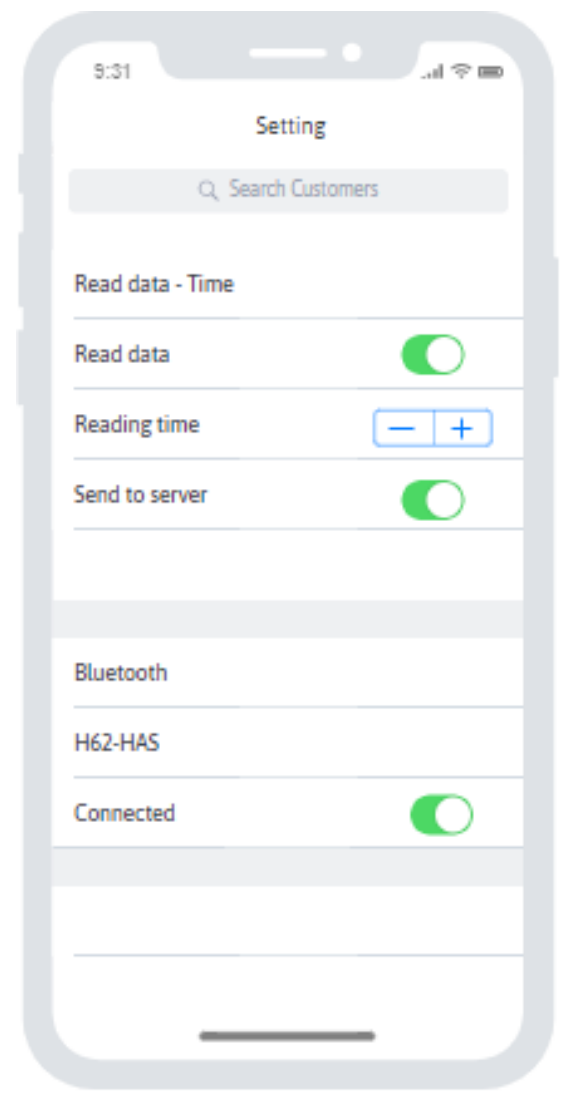

Fig. 9. Setup Screen. 


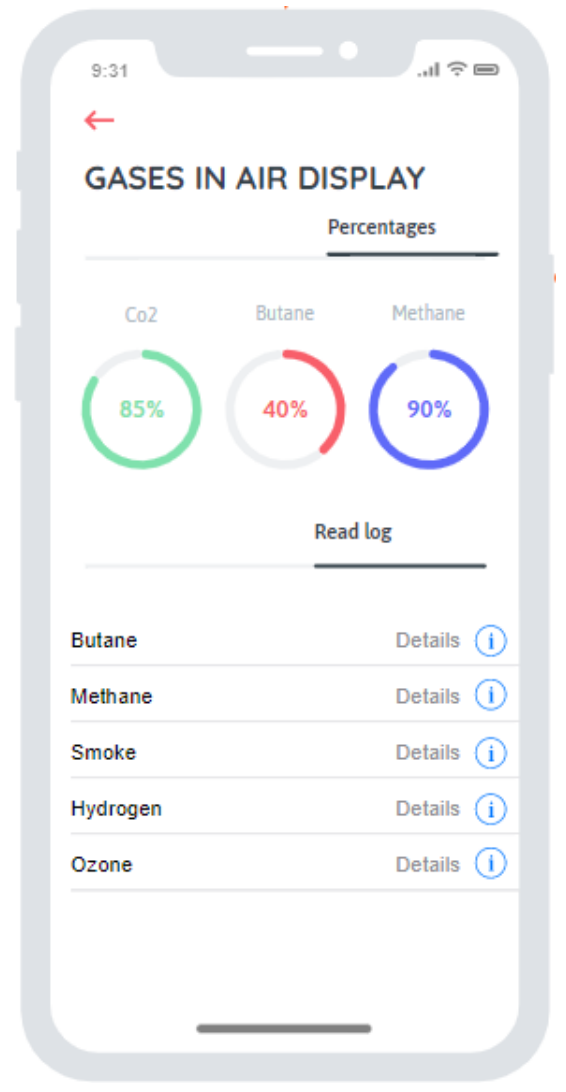

Fig. 10. Dashboard of Gases in the Air.

- Increment 3 - Pollution by Geographical Location. In this section, statistical data will be displayed that can be viewed by departments and districts (Fig. 8).

\section{5) Increments IoT:}

- Increment 1 - Sensor Integration with Arduino. The increase consists of the development of the electronic system that will be in charge of reading the environmental data through the electronic components mentioned in the Technologies section and the Arduino.

- Increment 2 - Integration of Arduino with Mobile device. The increase consists of integrating the Bluetooth module to the electronic system in order to be able to make the connection between the Bluetooth system and the mobile application.

\section{RESUlts AND Discussions}

This section presents the results obtained with respect to the methodology, technologies and case study, divided into two parts, which are the following:

\section{A. About the Case Study}

The results regarding the case study were highly favorable, the use of the Scrum methodology was proposed due to its Agile nature that allows the development of software quickly and in addition to that, some technologies that meet the proposed purpose were proposed.

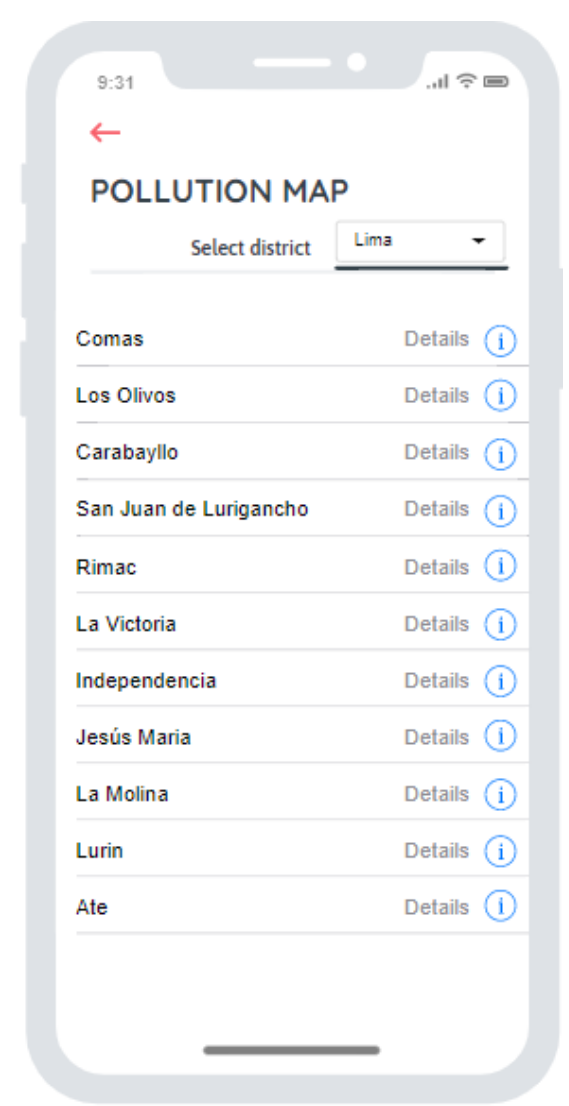

Fig. 11. Dashboard of Gases by Geographic Location.

As a result of the application of the case study, we obtained the following scheme where the IoT devices communicate with the cloud (Fire Base) that has a great diversity of services for data analysis, additionally provides a hosting for the application. As shown in Fig. 4, through sensors that are located in the upper part of the buildings, they obtain data on the indices of different polluting gases found in the environment that are sent to the server for analysis and interpretation, transforming into information that will be seen through the mobile application, allowing people to perceive in a simplified way the pollution rates around them.

The end user will be able to access the dashboard where they will view the types of polluting gases in the air as shown in Fig. 10 where we see detailed percentage graphs that explain the amount of butane, methane, smoke, etc. that exists in the environment where you are.

Likewise, you can see another board in Fig. 11 where you can search by geographical location for the types of pollutants that exist.

The results in relation to the technologies used were perfectly efficient and effective for the implementation, since the electronic sensors read the data of the medium accurately, the services provided by Fire Base are greatly used as it is a project related to emerging technologies. 


\section{B. About the Methodology}

The Scrum methodology was a great choice for the development of the research since its way of working allowed us to implement the solution in an agile way, open to the recurring change that was presented, unlike other methodologies such as RUP (Traditional methodology) [10].

In Scrum methodology, "Product Owner" will work closely with the team to detect and prioritize the functionality of the system [11].

Differences in methodologies: this part will detail the differences of using the agile methodology, as opposed to using other methodologies that exist. Table III will detail the differences that each methodology will have.

\section{TABle iII. Traditional Methodology vs. Agile Methodology}

\begin{tabular}{|l||l|}
\hline Traditional methodologies & Agile methodologies \\
\hline Predictive & Adaptive \\
\hline Rigid process & Flexible process \\
\hline Process-oriented & People-oriented \\
\hline $\begin{array}{l}\text { Little communication with the } \\
\text { client. }\end{array}$ & $\begin{array}{l}\text { Constant communication with } \\
\text { the client. }\end{array}$ \\
\hline $\begin{array}{l}\text { Software delivery at the end } \\
\text { of development. }\end{array}$ & Constant software deliveries \\
\hline Extensive documentation. & Little documentation. \\
\hline It is conceived as a project. & $\begin{array}{l}\text { A project is subdivided into } \\
\text { several smaller projects. }\end{array}$ \\
\hline
\end{tabular}

\section{CONCLUSions}

Finally we can conclude that the proposed objective was achieved, which is to carry out the mobile application with integration of the IoT to make people aware of the damage they cause to the environment. The scientific contribution provided by this research work is very important in the science environment since it is the basis for future projects that will have a great impact on society, projects that will be totally necessary to reduce environmental pollution and thus to save the planet. For future work it is proposed to improve the subject, apply technologies such as artificial intelligence or some other that makes the idea evolve. There are other alternatives to this solution to make people aware of the state of the environment, however those that exist are not available to people.

\section{REFERENCES}

[1] Q. Di, Y. Wang, A. Zanobetti, Y. Wang, P. Koutrakis, C. Choirat, F. Dominici, and J. D. Schwartz, "Air pollution and mortality in the medicare population," New England Journal of Medicine, vol. 376, no. 26, pp. 2513-2522, 2017.

[2] T. Bourdrel, M.-A. Bind, Y. Béjot, O. Morel, and J.-F. Argacha, "Cardiovascular effects of air pollution," Archives of cardiovascular diseases, vol. 110 , no. 11, pp. 634-642, 2017.

[3] A. Combes and G. Franchineau, "Fine particle environmental pollution and cardiovascular diseases," Metabolism, vol. 100, p. 153944, 2019.
[4] J. Xu, Y. Hu, and E. Miyoshi, "A consideration of media environment regarding air pollution problems in china: Based on the content analysis of the reports of "people's daily" from jan. 1,1970 to nov. 30,2011," in 2018 International Joint Conference on Information, Media and Engineering (ICIME), 2018, pp. 211-214.

[5] J. Park, Y. Oh, H. Byun, and C. Kim, "Low cost fine-grained air quality monitoring system using lora wan," in 2019 International Conference on Information Networking (ICOIN), 2019, pp. 439-441.

[6] B. Barazandeh and M. Rafieisakhaei, "A data analytics based approach for modeling the effects of a carbon market on the sustainable control of co2 emissions in latin america," in 2017 IEEE Conference on Technologies for Sustainability (SusTech), 2017, pp. 1-5.

[7] S. Pal, A. Ghosh, and V. Sethi, "Vehicle air pollution monitoring using iots," in Proceedings of the 16th ACM Conference on Embedded Networked Sensor Systems, 2018, pp. 400-401.

[8] S. Dhingra, R. B. Madda, A. H. Gandomi, R. Patan, and M. Daneshmand, "Internet of things mobile-air pollution monitoring system (iot-mobair)," IEEE Internet of Things Journal, vol. 6, no. 3, pp. 5577-5584, 2019.

[9] V. Sachdeva and L. Chung, "Handling non-functional requirements for big data and iot projects in scrum," in 2017 7th International Conference on Cloud Computing, Data Science \& Engineering-Confluence. IEEE, 2017, pp. 216-221.

[10] A. Srivastava, S. Bhardwaj, and S. Saraswat, "Scrum model for agile methodology," in 2017 International Conference on Computing, Communication and Automation (ICCCA), 2017, pp. 864-869.

[11] B. L. Romano and A. Delgado Da Silva, "Project management using the scrum agile method: A case study within a small enterprise," in 2015 12th International Conference on Information Technology - New Generations, 2015, pp. 774-776.

[12] A. Alhazmi and S. Huang, "A decision support system for sprint planning in scrum practice," in SoutheastCon 2018, 2018, pp. 1-9.

[13] G. Koç and M. Aydos, "Trustworthy scrum: Development of secure software with scrum," in 2017 International Conference on Computer Science and Engineering (UBMK), 2017, pp. 244-249.

[14] N. R. Darwish and S. Megahed, "Requirements engineering in scrum framework," International Journal of Computer Applications, vol. 149, no. 8, pp. 24-29, 2016.

[15] F. M. Fowler, "The sprint backlog," in Navigating Hybrid Scrum Environments. Springer, 2019, pp. 67-70.

[16] G. Jia, G. Han, J. Du, and S. Chan, "Pms: Intelligent pollution monitoring system based on the industrial internet of things for a healthier city," IEEE Network, vol. 33, no. 5, pp. 34-40, 2019.

[17] M. M. Rahman, M. A. H. Rimon, M. A. Hoque, and M. R. Sammir, "Affordable smart ecg monitoring using arduino bluetooth module," in 2019 1st International Conference on Advances in Science, Engineering and Robotics Technology (ICASERT), 2019, pp. 1-4.

[18] K. Arasu, "Automated experimental procedure using sensors and arduino," in 2017 International Conference on Inventive Computing and Informatics (ICICI), 2017, pp. 383-387.

[19] S. Dhingra, R. B. Madda, A. H. Gandomi, R. Patan, and M. Daneshmand, "Internet of things mobile-air pollution monitoring system (iot-mobair)," IEEE Internet of Things Journal, vol. 6, no. 3, pp. 5577-5584, 2019.

[20] S. Dhingra, R. B. Madda, A. H. Gandomi, R. Patan, and M. Daneshmand, "Internet of things mobile-air pollution monitoring system (iot-mobair)," IEEE Internet of Things Journal, vol. 6, no. 3, pp. 5577-5584, 2019.

[21] W. Li, C. Yen, Y. Lin, S. Tung, and S. Huang, "Justiot internet of things based on the firebase real-time database," in 2018 IEEE International Conference on Smart Manufacturing, Industrial Logistics Engineering (SMILE), 2018, pp. 43-47.

[22] G. A. Amagsila, M. E. Cabuhat, J. E. Tigbayan, E. Uy, and E. Ramirez, "A framework for mobile application of flood alert monitoring system for vehicle users using arduino device," in 2017IEEE 9th International Conference on Humanoid, Nanotechnology, Information Technology, Communication and Control, Environment and Management (HNICEM), 2017, pp. 1-6. 